\title{
Research of Doubly Fed Induction Wind Power Generation System Control and Experimental Platform Based on DSP
}

\author{
Tiantian $\mathrm{Xu}^{1, \mathrm{a}}$,Dongdong $\mathrm{Li}^{2, \mathrm{~b}}$ \\ ${ }^{1}$ Yangpu District Changyang Road No.2588,Shanghai,China \\ ${ }^{2}$ Yangpu District Changyang Road No.2588,Shanghai,China

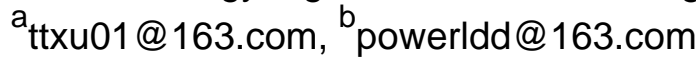

Key words: Doubly fed induction generator; Wind power generation; Converter control.

\begin{abstract}
This paper studied doubly fed induction wind power generation system and modeldits wind turbine and generation. The vector control algorithem was proposed to conduct MPPT(Maximum Power Point Tracking) strategy.An experimental platform was built based on DSP of TMS320F28335 series.The experimental result shows that the system can realize VSCF(variable speed constant frequency) and MPPT,and has excellent dynamical and static performance.
\end{abstract}

\section{Introduction}

In recent years,variable speed constant frequency(VSCF) wind power generation system with doubly fed induction generator(DFIG) gradually become the mainstream.This paper discusses the maximum power pointtracking (MPPT) control of DFIG by vector control stratrgy [1,2].

To research doubly fed induction wind power generation system in laboratory,a doubly fed wind power generation experimental platform is described in the paper.Verifies the DFIG grid-connection control strategy through hardware experimental under the condition of laboratory allows.

\section{Mathematical modle of DFIG wind power generation system}

Doubly fed induction wind power generation system consists of the following sections: wind turbine, doubly fed induction generator, rotor-side converter (RSC), grid-side converter (GSC) and control part. A system schematic diagram is shown in Fig. 1.

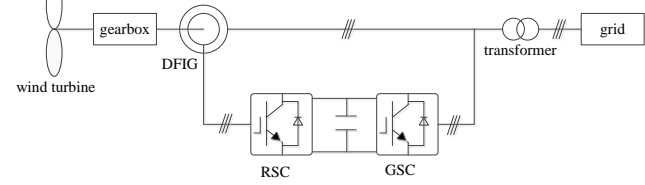

Fig. 1 Schematic of DFIG wind power system

Mathematic model of wind turbine.The power and torque equations are shown in Eq. 1 [3]:

$\left\{\begin{array}{l}P=\frac{1}{2} C_{p} \rho A v_{w}^{3}=\frac{1}{2} C_{p} \rho \pi R^{2} v_{w}^{3} \\ T=\frac{P}{\omega}=\frac{1}{2} C_{T} \rho \pi R^{2} v_{w}^{3}\end{array}\right.$.

where $P$ is the wind turbine output mechanical power, $T$ is the wind turbine output torque, $\rho$ is the air density, takes it as $1.25 \mathrm{~kg} / \mathrm{m}^{3}$ generally, $C_{p}$ stands for rotor power coefficient, $R$ is radius of the impeller, $A$ is the impeller swept area, $C_{T}$ stands for torque coefficient.

$C_{p}$ is an important parameter of characterization of wind turbine efficiency. Another important parameter of wind turbine is tip speed ratio, $\lambda$. The expression of $\lambda$ is shown in Eq. 2 :

$$
\lambda=\frac{u}{v}=R \frac{\omega}{v}=\frac{2 R \pi n}{60 v} .
$$

Where $\lambda$ is tip speed ratio, $R$ is radius of the impeller, $\omega$ stands for rotor ratatingangular velocity, $n$ stands for the speed of the fan.

Under a fixed wind speed, there exists a $\lambda_{\text {opt }}$ which makes $C_{p}$ get the maximum $C_{\text {pmax }}$. Different wind speed corresponding to their maximum output power respectively. 
Mathematical model of DFIG.According to the generator practice, the mathematical model of DFIG $d$ - $q$ reference frame can be expressed as follows [4]:

1) Voltage equations

The stator voltage equation:

$\left\{\begin{array}{l}u_{d s}=R_{s} i_{d s}+p \psi_{d s}-\omega_{1} \psi_{q s} \\ u_{q s}=R_{s} i_{q s}+p \psi_{q s}+\omega_{1} \psi_{d s}\end{array}\right.$.

The rotor voltage equation:

$\left\{\begin{array}{l}u_{d r}=R_{r} i_{d r}+p \psi_{d r}-\omega_{2} \psi_{q r} \\ u_{q r}=R_{r} i_{q r}+p \psi_{q r}+\omega_{2} \psi_{d r}\end{array}\right.$.

2) Flux linkage equations

The stator flux linkage equation:

$\left\{\begin{array}{l}\psi_{d s}=L_{l s} i_{d s}+L_{m}\left(i_{d s}+i_{d r}\right)=L_{s} i_{d s}+L_{m} i_{d r} \\ \psi_{q s}=L_{l s} i_{q s}+L_{m}\left(i_{q s}+i_{q r}\right)=L_{s} i_{q s}+L_{m} i_{q r}\end{array}\right.$.

The rotor flux linkage equation:

$\left\{\begin{array}{l}\psi_{d r}=L_{l r} i_{d r}+L_{m}\left(i_{d r}+i_{d s}\right)=L_{r} i_{d r}+L_{m} i_{d s} \\ \psi_{q r}=L_{l r} i_{q r}+L_{m}\left(i_{q r}+i_{q s}\right)=L_{r} i_{q r}+L_{m} i_{q s}\end{array}\right.$.

Substituting flux linkage equations into voltage equations, then the voltage- current equation under $d$-qreference frame can be written as:

$\left[\begin{array}{l}u_{d s} \\ u_{q s} \\ u_{d r} \\ u_{q r}\end{array}\right]=\left[\begin{array}{cccc}R_{s}+L_{s} p & -\omega_{1} L_{s} & L_{m} p & -\omega_{1} L_{m} \\ \omega_{1} L_{s} & R_{s}+L_{s} p & \omega_{1} L_{m} & L_{m} p \\ L_{m} p & -\omega_{2} L_{m} & R_{r}+L_{r} p & -\omega_{2} L_{r} \\ \omega_{2} L_{m} & L_{m} p & \omega_{2} L_{r} & R_{r}+L_{r} p\end{array}\right]\left[\begin{array}{c}i_{d s} \\ i_{q s} \\ i_{d r} \\ i_{q r}\end{array}\right]$.

3) Torque equation and motion equation

The electromagnetic torque equation:

$T_{e}=\frac{3}{2} n_{p} L_{m}\left(i_{q s} i_{d r}-i_{d s} i_{q r}\right)=\frac{3}{2} n_{p}\left(\psi_{q r} i_{d r}-\psi_{d r} i_{q r}\right)$.

The motion equation:

$$
T_{m}-T_{e}=J \frac{d \omega_{m}}{d t}=J \frac{d^{2} \theta_{m}}{d t^{2}} .
$$

In Eq. $3 \sim$ Eq. 9, subscript $d$ and q represent $d$ axis and $q$ axis components respectively. Subscript $\mathrm{s}$ and $\mathrm{r}$ represent stator and rotor components respectively. $\omega_{2}=\omega_{1}-\omega_{\mathrm{r}}$ is the slip velocity.

Fig. 2 shows the DFIG dynamic equivalent circuit under $d$ - $q$ reference frame.

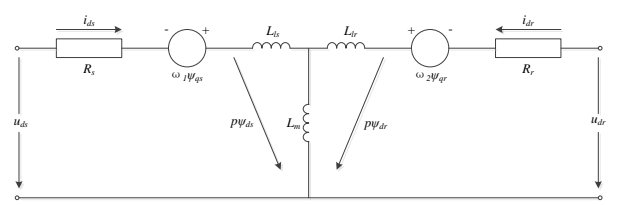

(a) $d$ axis equivalent circuit 


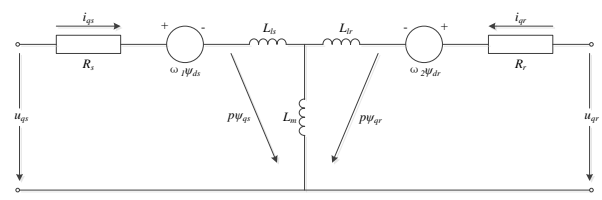

(b) $q$ axis equivalent circuit

Fig. 2 Dynamic equivalent circuit of DFIG

\section{Converter control strategy}

The RSC inject excitation current into DFIG rotor winding, to realize MPPT and regulate the reactive power of stator side. The GSC control the DC-link voltage at instruction value, and can regulate the grid side power factor.

RSC control.This paper uses stator flux oriented vector control,assuming that grid is three-phase symmetrical [5].

DFIG stator side output active and reactive power are linearly related to the $q$ axis and $d$ axis component of rotor current respectively. So $i_{q r}$ and $i_{d r}$ respectively can regulate active and reactive power independently.Fig. 3 shows a schematic block diagram for RSC control using hysteresis current control.

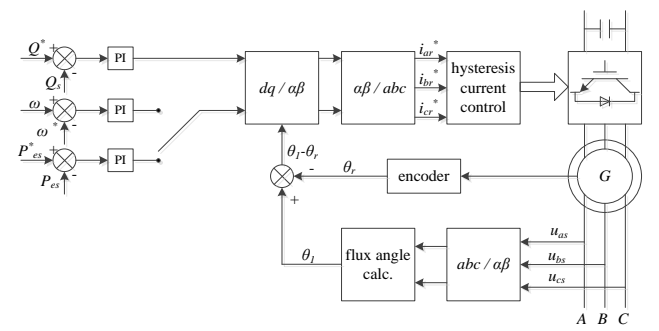

Fig. 3 Vector control structure for RSC

In power control loop, comparing the active power demand $P_{e s}{ }^{*}$ and reactive power demand $Q_{s}{ }^{*}$ with power feedback value $P_{e s}$ and $Q_{s}$, inputingthe difference value into output limitedPIcontroller,then output the rotor side current component $i_{d r}{ }^{*}$ and $i_{q r}{ }^{*}$. Active power control can be equivalently conversed to speed control, according to the current wind speed to calculate corresponding optimum speed as the speed loop demand value $\omega^{*}$. Then comparing it with generator practical speed $\omega$, input the error into output limited PI controller, get the rotor current demand value $i_{d r}{ }^{*}$ and $i_{q r}{ }^{*}$ under $d-q$ frame.

GSC control. The objective of the grid side converter is to keep the DC-link voltage constant regardless of the magnitude and direction of the rotor power. Fig. 4 shows the schematic of the grid side converter [6].

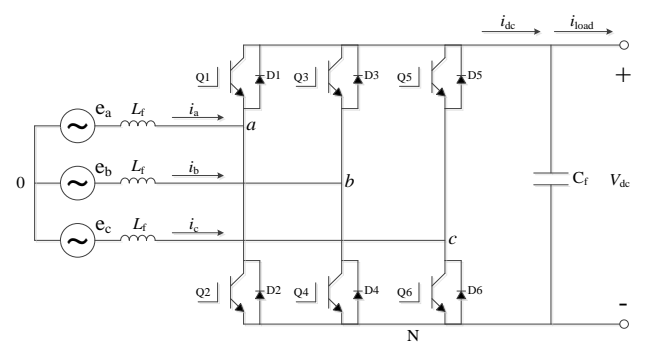

Fig. 4 Grid side converter arrangement

A vector control is used, with a reference frame oriented along the grid voltage vector position. The $d$ axis and $q$ axis component of grid voltage can be written as:

$\left\{\begin{array}{l}e_{d}=E \\ e_{q}=0\end{array}\right.$.

Where $E$ is the amplitude of grid voltage vector.

The active and reactive power of grid side converter under $d-q$ frame can be written as: 


$$
\left\{\begin{array}{l}
P=\frac{3}{2}\left(e_{d} i_{d}+e_{q} i_{q}\right)=\frac{3}{2} e_{d} i_{d} \\
Q=\frac{3}{2}\left(e_{q} i_{d}-e_{d} i_{q}\right)=-\frac{3}{2} e_{d} i_{q}
\end{array} .\right.
$$

According to the above analysis can determine the GSC control strategy, shows in Fig. $5 . i_{d}{ }^{*}$ can be derived from the error of DC-link voltage demand value $u_{d c}{ }^{*}$ and measured voltage $u_{d c}$ through a PI controller. The value of $i_{q}{ }^{*}$ is determined by the power facor. Comparingi $i_{d}{ }^{*}$ and $i_{q}{ }^{*}$ with corresponding current feedback value, output $u_{d}$ and $u_{q}$ through a PI controller. Then calculating $u_{d}, u_{q}$ with corresponding decoupling compensation term $\Delta u_{d}, \Delta u_{q_{*}}$ and grid voltage feedforward compensation term $e_{d}, e_{q}$ to get converter AC side voltage demand $u_{d}{ }^{*}, u_{q}{ }^{*}$.

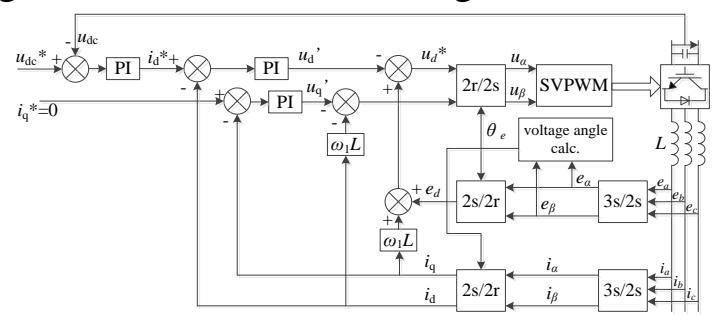

Fig. 5 Vector control structure for GSC

\section{DFIG wind power generation experimental system}

A doubly fed induction wind power generation experimental system and relevant experiments are designed.Fig. 6 shows the schematic of experimental system.

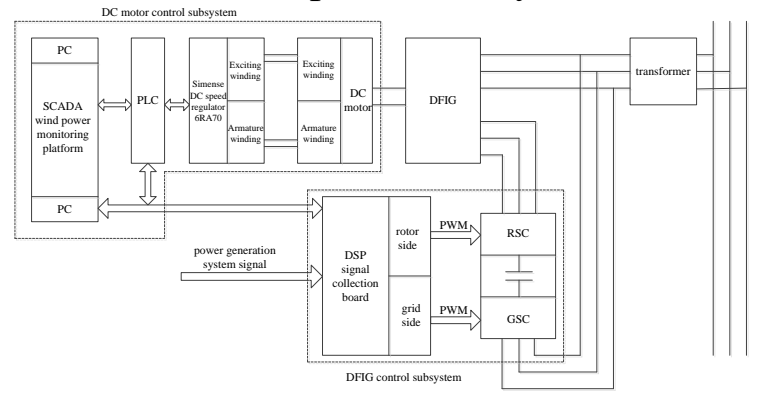

Fig. 6 Schematic of experimental system

This paper uses DC motor to simulate wind turbine.TI DSP - TMS320F28335 is used to control converters and process collected signals.

Given wind velocityincreases from $3 \mathrm{~ms}^{-1}$ to $12 \mathrm{~ms}^{-1}$, the wind speed once every 20 seconds to change, each adds $1 \mathrm{~ms}^{-1}$. The PC works out optimal rotating speed and torque of maxmim power point baesd on the wind velocity and wind turbine parameters, then controls DC motor to drive DFIG. Fig. 7, Fig. 8show thesteady-state grid-connected voltage current curves. Fig. 9 is wind velocity setting signal, Fig. 10 shows the power trend curve of MPPT experiment. The parameters of the experimental system are shown in Table 1.

Table 1 The experimental system specific parameter statistics

\begin{tabular}{c|c|c}
\hline & DC motor & DFIG \\
\hline Rated power [kW] & 15 & 7.5 \\
\hline Rated voltage [V] & 440 & 380 \\
\hline Rated current [A] & 40 & 20 \\
\hline Rated rotate velocity [rpm] & 1500 & 705 \\
\hline Excitation voltage [V] & 180 & -- \\
\hline Excitation current [A] & 3.52 & -- \\
\hline
\end{tabular}

The radius of simulating wind turbine is $2 \mathrm{~m}$, the pitch angle is set to zero. 


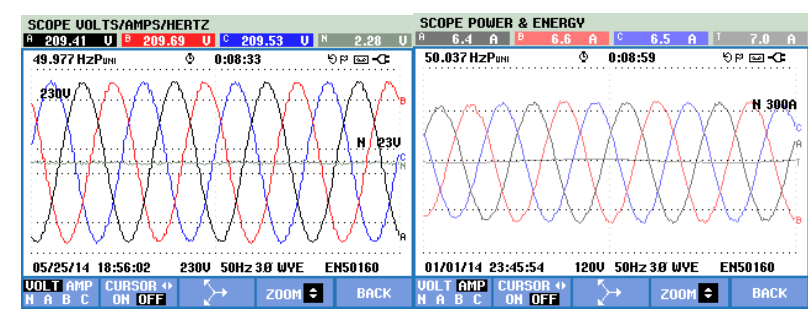

Fig. 7 Grid-connected voltage curveFig. 8 Grid-connected current curve

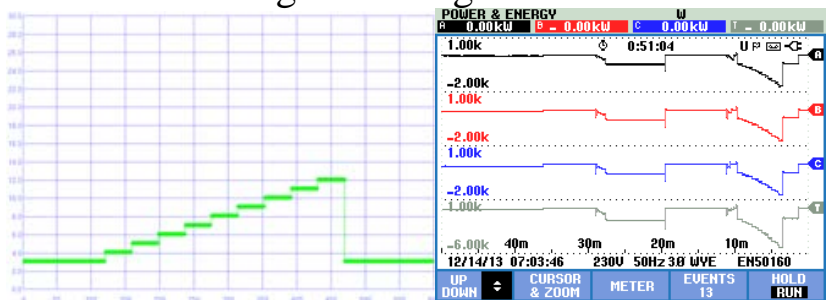

Fig. 9 Wind velocity setting signal Fig. $10 \quad$ MPPT power trend curve

From Fig. 7 and Fig. 8, experimental results shows that during steady-state conditions ,the current frequency is $50 \mathrm{~Hz}$ with small current harmonic, which proves the control strategy has good control effect. When wind velocitysteps up, Fig. 10 shows DFIG realizes MPPT.

\section{Summary}

The close-loop controlling system is made up of the vector control model and doublyfed induction generator.Rrealizing MPPT by controlling the RSC and GSC. The rationality of the proposed control stratrgy is verified by experiments, and the experimental results shows a good dynamic and static control properties.

\section{References}

[1] R. Pena, J.C. Clare and G.M. Asher: Doubly fed induction generator using back-to-back PWM converters and its application to variable speed wind-energy generation. IEE Proc- Electr. Power Appl., Vol. 143 (1996),p. 231-233

[2] G.A. Smith, K. Nigim and A.Smith: Wind-energy recovery by a static Scherbius induction generator. IEE Proc. C, Vol. 128 (1981), p.317-324

[3] A.B. Sankar: Performance Analysis of PWM Inverter for Wind Driven Doubly Fed Induction Generator. IEEE ICAESM-2012, p. 657

[4] E. Tremblay, S. Atayde and A. Chandra: Comparative Study of Control Strategies for the Doubly Fed Induction Generation in Wind Energy Conversion System: A DSP-Based Implementation Approach. IEEE Transactions on Sustainable Energy, Vol. 2(2011), p. 289-292

[5] A. T. G. Tapia: Modeling and Control of a Wind Turbine Driven Doubly Fed Induction Generator. IEEE Trans. On Energy Conversion. Vol.18(2003), p.194-204

[6] E. Tremblay, A. Chandra and P. Lagace: Grid-side converter control of DFIG wind turbines to enhance power quality of distribution network. IEEE Power Engineering Society Generak Meeting (PES 2006) 